\title{
IDENTIFICATION SYSTEM FOR THE TECHNICAL CONDITION OF GAS TURBINE ENGINES OF AIRCRAFT
}

\author{
Arif Pashayev, Djakhangir Askerov, Ramiz Sadiqov ${ }^{1}$, Parviz Abdullayev² \\ Azerbaijan National Academy of Aviation, AZ1045, Azerbaijan, Baku, Bina, $25^{\text {th }} \mathrm{km}$ \\ E-mail: ${ }^{1}$ sadixov@mail.ru, ${ }^{2}$ a_parviz@azeronline.com
}

Received 07 February 2006, accepted 01 December 2008

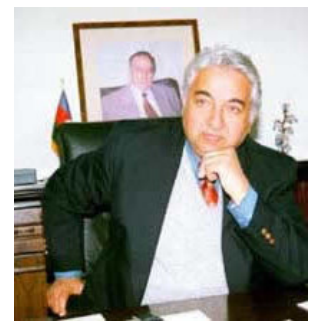

Arif PASHAYEV, Prof Eng Academician

Research interests: physical fields in solids, physics of the matter structure, and modern technique of physical research. Present position: rector of the National Academy of Aviation.

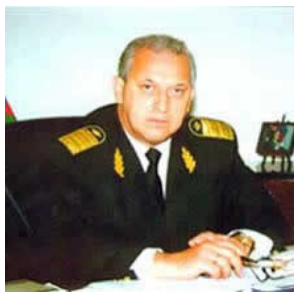

\section{Djakhangir ASKEROV}

Research interests: modeling the aviation transporting systems on the basis of modern mathematical methods and techniques.

Present position: senior lecturer, head of "Manufacture of aviation transport" Department of the National Academy of Aviation.

Ramiz Ali Cabar oqlu SADIQOV, Prof Dr Habil

Date and place of birth: March 1949, Baku Azerbaijan Republic.

Education: 1971 - Azerbaijan State Pedagogy Institute, mathematician; 1985 - Institute of Cybernetics of Azerbaijan, PhD, mathematics; 1996 - Academy of Sciences, Doctor of science,Higher Attestation Committee of Russian Federation, Moscow.

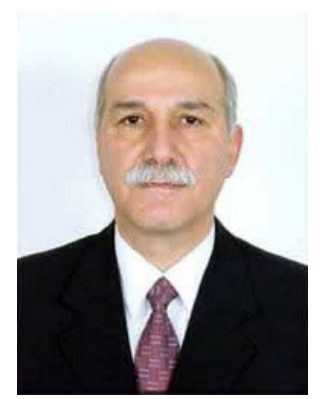

Work experience: 1998 - present Chairman and Full Professor of Department of Computer Science and Mathematical Simulation, National Aviation Academy of Azerbaijan, Baku; 1989-1998 Head and Associate Professor of computer center of Azerbaijan Technical University, Baku; 1977-1989 Head of computer center of Scientific Research Institute "Neft - Gaz - Avtomat," Baku; 1972-1977 Mathematician - programmer at Applied Mathematics Institute named after M.V. Keldish, Moscow; RAS.

Affiliations and functions: taught courses: Mathematical modeling and control multiconnected systems; System theory and identification; Numerical methods; Introduction to computer science; Soft computing: fuzzy logic, neural networks, genetic algorithm, chaos and fractals.

Professional memberships: a member - academician of International Academy of Sciences, Russian section; A member - American Science Mechanical Engineering; A member - International Union of Machine Builders.

Research interests: development of mathematical models for various physical phenomena and technological processes and development numerical methods for their solving. Mathematical simulation and identification application modern technologies including Soft Computing.

Publications: the number of total published scientific works is above 250; papers on 30 scientific conferences. Present position: Chairman and Full Professor of Department of Computer Science and Mathematical Simulation, National Aviation Academy of Azerbaijan.

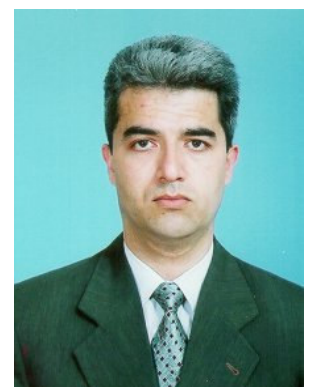

Parviz Shahmurad ABDULLAYEV, Assoc Prof DPh Eng

Date of birth: 1967.

Research interests: aircraft gas turbine engines condition monitoring methods on the basis of modern mathematical methods and techniques (neural networks, fuzzy logic).

Present position: head of Design and Exploitation of Aircrafts and Aviation Engines Department of the Azerbaijan National Academy of Aviation. 


\begin{abstract}
In this paper, it is shown that the use of probability-statistic methods, especially at the early stage of diagnosing the technical condition of aviation gas turbine engines (GTE) when the flight information has fuzzy and limitation and uncertainty properties, is unfounded. Hence the efficiency of the use of Soft Computing methods-fuzzy logic and neural networks at these diagnostic stages is considered. Training with high accuracy of fuzzy multiple linear and non-linear models (fuzzy regression equations) which received on the statistical fuzzy data basis is made. Thus, for to make a more adequate model of the technical condition of GTE, the dynamics changes of skewness and kurtosis coefficients are analysed. Research of skewness and kurtosis coefficients shows, that the statistical distributions of the work parameters of GTE have a fuzzy character. Hence, consideration of fuzzy skewness and kurtosis coefficients is expedient.

Investigation of the basic characteristics of the changes in the dynamics of the work parameters of GTE allows to draw the conclusion that it is necessary to use fuzzy statistical analysis during the preliminary identification of the technical condition of engines.

Research of changes in the values of correlation coefficients also demonstrates their fuzzy character. Therefore for models choice the application of the Fuzzy Correlation Analysis results is offered. The fuzzy multiple correlation coefficient of fuzzy multiple regression is considered for checking the adequacy of models.

At the information sufficiency is offered to use recurrent algorithm of aviation GTE technical condition identification (hard computing technology is used) on measurements of input and output parameters of the multiple linear and nonlinear generalised models at presence of noise measured (the new recursive Least Squares Method (LSM)).

The system that is developed to monitor the condition of GTE provides stage-by-stage estimation of the technical condition of an engine. As an application of this technique, an estimation of the new operating aviation engine temperature condition was made.
\end{abstract}

Keywords: aviation gas turbine engine, fuzzy logic and newral networks, fuzzy statistics, fuzzy coefficient of multiple correlation.

\title{
Nomenclature
}

$\begin{array}{ll}H & \text { Flight altitude } \\ M & \text { Mach number } \\ T_{H}^{*} & \text { Atmosphere temperature } \\ p_{H}^{*} & \text { Atmosphere pressure } \\ n_{L P} & \text { Low pressure compressor speed (RPM) } \\ T_{4}^{*} & \text { Exhaust gas temperature } \\ G_{T} & \text { Fuel flow } \\ p_{T} & \text { Fuel pressure } \\ p_{M} & \text { Oil pressure } \\ T_{M} & \text { Oil temperature } \\ V_{B S} & \text { Back support vibration } \\ V_{F S} & \text { Forward support vibration } \\ a_{1}, a_{2}, a_{3}, \ldots & \text { Regression coefficients in initial linear multiple regression equation of model of GTE condition } \\ a_{1}^{\prime}, a_{2}^{\prime}, a_{3}^{\prime}, \ldots & \text { Regression coefficients in actual linear multiple regression equation of model of GTE condition } \\ \tilde{a}_{1}, \tilde{a}_{2}, \tilde{a}_{3}, \ldots & \text { Fuzzy regression coefficients in linear multiple regression equation of model of GTE condition } \\ \tilde{X}, \tilde{Y} & \text { Measured fuzzy input and output parameters of model of GTE condition } \\ r_{X, Y} & \text { Correlation coefficients between GTE work parameters } \\ \tilde{r}_{X, Y} & \text { Fuzzy correlation coefficients between GTE work parameters } \\ \otimes & \text { Fuzzy multiply operation } \\ \text { ini } & \text { Initial } \\ \text { act } & \text { Actual } \\ \mathrm{GTE} & \text { Gas turbine engine } \\ \mathrm{ADS} & \text { Automatic diagnostic system } \\ \mathrm{CIS} & \text { Commonwealth of independent states } \\ \mathrm{NN} & \text { Neural network } \\ \mathrm{FL} & \text { Fuzzy logic } \\ \mathrm{LSM} & \text { Least squares method } \\ & \end{array}$

$a_{1}, a_{2}, a_{3}, \ldots \quad$ Regression coefficients in initial linear multiple regression equation of model of GTE condition

$a_{1}, a_{2}, a_{3}, \ldots \quad$ Regression coefficients in actual linear multiple regression equation of model of GTE condition

$\tilde{a}_{1}, \tilde{a}_{2}, \tilde{a}_{3}, \ldots \quad$ Fuzzy regression coefficients in linear multiple regression equation of model of GTE condition 


\section{Introduction}

One of the important maintenance requirements for the modern aviation gas turbine engine (GTE) on condition is the presence of an efficient parametric technical diagnostic system. As is known, the diagnostic problem of the GTE of some aircraft is mainly that the onboard systems of the objective control don't register all engine work parameters. This circumstance causes the need for additional manual registration of other parameters of GTE work. Consequently, there is the necessity to create a diagnostic system that provides the possibility of monitoring the condition of a GTE and making an exact recommendation about the further maintenance of the GTE by using registered data either on manual record and onboard recorders.

In the subdivisions of CIS airlines, various automatic diagnostic systems (ADS) are currently used to determine the technical conditions of GTE. The essence of ADS methods is mainly to form flexible ranges for the recorded parameters as the result of engine operating time and to compare the recorded meaning of parameters with their point or interval estimations (values).

However, it should be noted that statistic data processing using the aforementioned method is conducted by the preliminary allowance of the recorded parameters meaning normal distribution. This allowance affects the reliability of the monitoring of the technical condition of GTE and causes of the error decision in the GTE diagnostic and operating process (Pashayev et al. 2004a, Pashayev et al. 2003, Abdullayev et al. 2005).

Moreover, some identical combination of changes in the various work parameters of GTE can be caused by different malfunctions. This complicates the location of the defect.

\section{Fuzzy-neural identification system of technical condition of GTE (Preliminary stage)}

A combined diagnostic method of monitoring the condition of GTE based on the evaluation of engine parameters by soft computing methods, mathematical statistics (high order statistics), and regression analysis is suggested. The method provides stage-by-stage (three stages) evaluation of the technical conditions of GTE (Fig 1). Experimental investigation conducted by manual records shows that, at the beginning of monitoring during $40 \div 60$ measurements, accumulated values of recorded parameters of GTE in good working order are not normal distribution.

Consequently, in the first stage of the diagnostic process (at the preliminary stage of GTE operation) when initial data is insufficient and fuzzy, GTE condition is estimated by soft computing methods: the fuzzy logic (FL) method and neural networks (NN). In spite of the rough parameters estimations of GTE conditions, the privilege of this stage is the possible creation of an initial image (initial condition) of the engine on the indefinite information.
As is known, one of the methods used to estimate the technical condition of GTE is the control of the temperature of exhaust gas and analysis of the trends in the changes in these values during operation. The application of various mathematical models described by regression equations for estimating the condition of GTE used in aviation is presented by L. A. Ivanov and S. M Doroshko (Ivanov et al. 2003, Doroshko 1984).

Let us consider mathematical linear and non-linear models of aviation GTE temperature described by fuzzy regression equations:

$$
\begin{gathered}
\tilde{Y}_{i}=\sum_{j=1}^{n} \tilde{a}_{i j} \otimes \tilde{x}_{j} ; i=\overline{1, m}, \\
\tilde{Y}_{i}=\sum_{r, s} \tilde{a}_{r s} \otimes \tilde{x}_{1}^{r} \otimes \tilde{x}_{2}^{s} ; r=\overline{1, l} ; s=\overline{1, l} ; r+s \leq l,
\end{gathered}
$$

where $\tilde{Y}_{i}$ is the fuzzy output parameter (e.g. GTE exhaust gas temperature $T_{4}^{*}$ ), $\tilde{x}_{j}$ or $\tilde{x}_{1}, \tilde{x}_{2}$ are input parameters $\left(H, M, T_{H}^{*}, p_{H}^{*}, n_{L P}, G_{T}, p_{T}, p_{M}, T_{M}, V_{B S}, V_{F S}\right)$, and $\tilde{a}_{i j}$ and $\tilde{a}_{r s}$ are required fuzzy parameters (fuzzy regression coefficients).

The general task is to define the parameters of the fuzzy values $\tilde{a}_{i j}$ and $\tilde{a}_{r s}$ of the equations (1) and (2) on the basis of the fuzzy statistical experimental data: input co-ordinates $\tilde{x}_{j}$ and $\tilde{x}_{1}, \tilde{x}_{2}$ and the output co-ordinates $\tilde{Y}$ of the model.

Let us consider the decision of the given tasks by using FL and NN (Abasov et al. 1998, Yager et al. 1994, Hassoun 1995).

NN consists of interconnected fuzzy neurons sets. When using NN to solve equations (1) and (2), the input signals of the network are accordingly fuzzy values of variable $\tilde{X}=\left(\tilde{x}_{1}, \tilde{x}_{2}, \ldots, \tilde{x}_{n}\right), \tilde{X}=\left(\tilde{x}_{1}, \tilde{x}_{2}\right)$, and output $\tilde{Y}$.

As the parameters of the network are fuzzy values of parameters $\tilde{a}_{i j}$ and $\tilde{a}_{r s}$, we shall present fuzzy variables in the triangular form for which membership functions are calculated with the formula:

$$
\mu(x)=\left\{\begin{array}{l}
1-(\bar{x}-x) / \alpha, \text { if } \bar{x}-\alpha<x<\bar{x} \\
1-(\bar{x}-x) / \beta, \quad \text { if } \bar{x}<x<\bar{x}+\beta \\
0, \quad \text { otherwise } .
\end{array}\right.
$$

At the identification task decision of parameters $\tilde{a}_{i j}$ and $\tilde{a}_{r s}$ for equations (1) and (2) using NN, the basic problem is training the parameters $\tilde{a}_{i j}$ and $\tilde{a}_{r s}$. For training the values of parameters, we shall take advantage of a $\alpha$-cut (Hassoun 1995). 


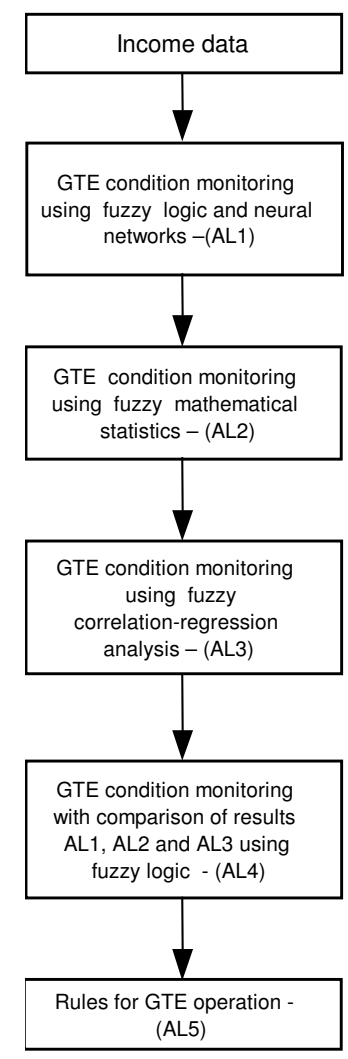

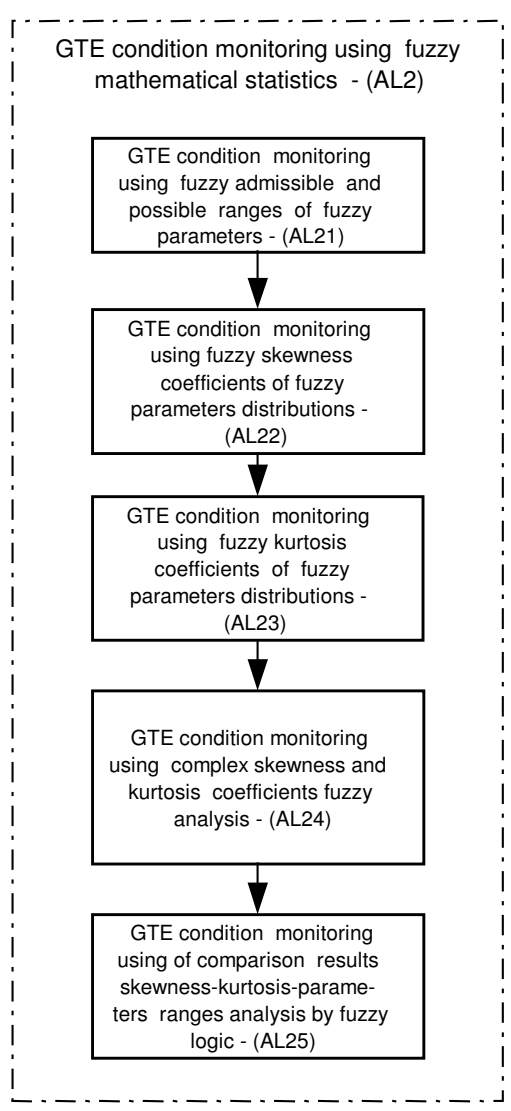

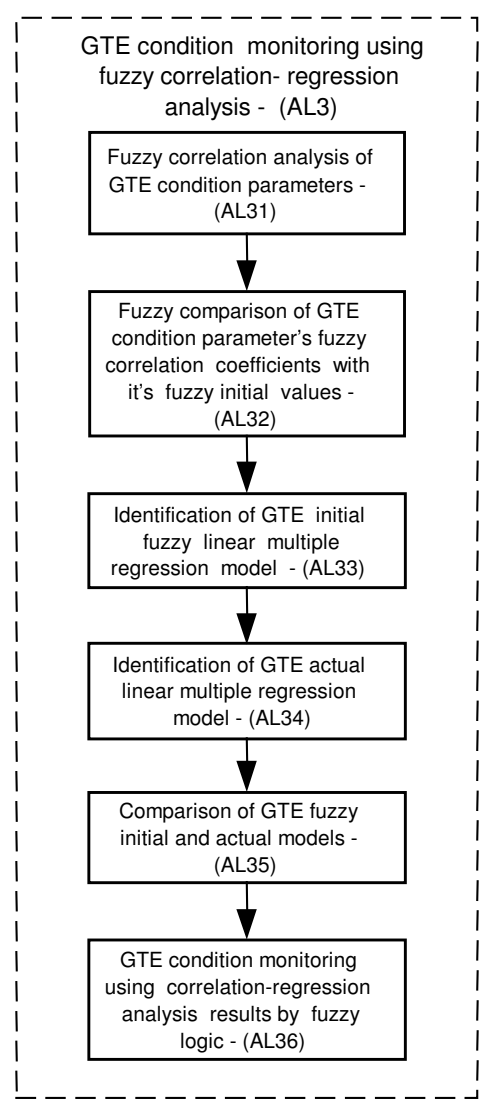

Fig 1. Flow chart of aircraft gas turbine engine fuzzy-parametric diagnostic algorithm

We suppose there are statistical fuzzy data received on the basis of experiments. On the basis of these input and output data training pairs $(\tilde{X}, \tilde{T})$ are made for training a network. For construction of process model on the input of $\mathrm{NN}$ gives input signals $\tilde{X}$, and further outputs are compared with reference output signals $\tilde{T}$ (Fig 2).

After comparison, the deviation value is calculated:

$$
\tilde{E}=\frac{1}{2} \sum_{j=1}^{k}\left(\tilde{Y}_{j}-\tilde{T}_{j}\right)^{2}
$$

With application $\alpha$-cut for the left and right part of

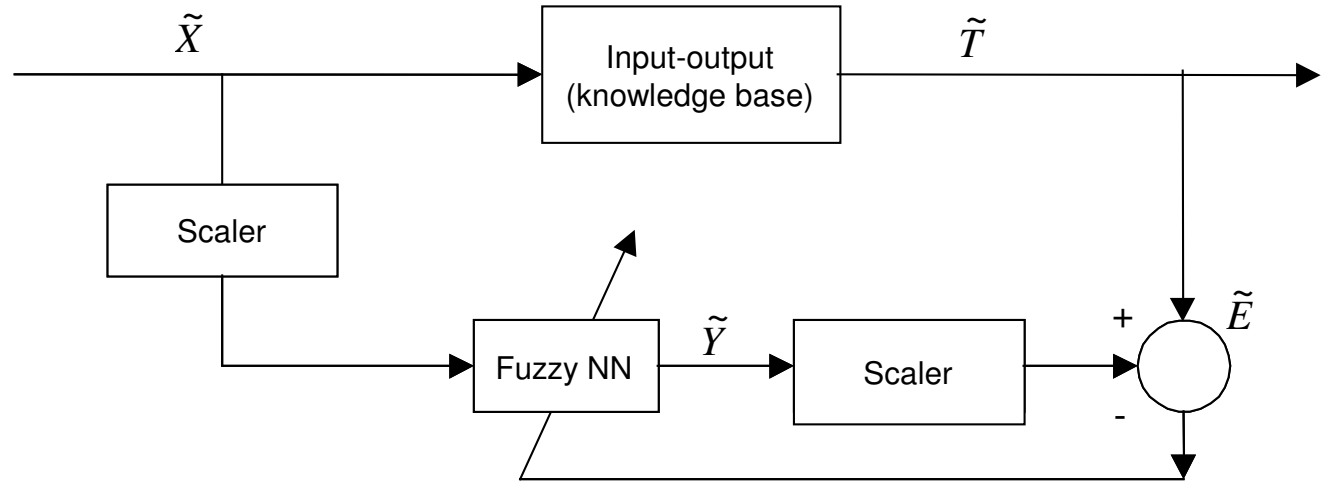

Fig 2. Neural identification system deviation value are calculated with the formulas

$$
\begin{gathered}
E_{1}=\frac{1}{2} \sum_{j=1}^{k}\left[y_{j 1}(\alpha)-t_{j 1}(\alpha)\right]^{2}, \\
E_{2}=\frac{1}{2} \sum_{j=1}^{k}\left[y_{j 2}(\alpha)-t_{j 2}(\alpha)\right]^{2}, E=E_{1}+E_{2},
\end{gathered}
$$

where

$$
\tilde{y}_{j}(\alpha)=\left[y_{j 1}(\alpha), y_{j 2}(\alpha)\right] ; \quad \tilde{T}_{j}(\alpha)=\left[t_{j 1}(\alpha), t_{j 2}(\alpha)\right] .
$$


If for all training pairs the deviation value $E$ is less than given, then training (correction) parameters of the network come to an end (Fig 3). In the opposite case, it continues until value $E$ reaches a minimum.

The correction of network parameters for the left and right parts is carried out as follows:

$$
a_{r s 1}^{n}=a_{r s 1}^{o}+\gamma \frac{\partial E}{\partial a_{r s}}, \quad a_{r s 2}^{n}=a_{r s 2}^{o}+\gamma \frac{\partial E}{\partial a_{r s}},
$$

where $a_{r s 1}^{o}, a_{r s 1}^{n}, a_{r s 2}^{o}, a_{r s 2}^{n}$ are the old and new values of the left and right parts NN parameters, $\tilde{a}_{r s}=\left[a_{r s 1}, a_{r s 2}\right]$ and $\gamma$ is training speed.

The structure of the NN for the identification of the parameters of equation (1) is given in figure 4.

For equation (2), we shall consider a concrete special case as a regression equation of the second order

$$
\tilde{Y}=\tilde{a}_{00}+\tilde{a}_{10} \tilde{x}_{1}+\tilde{a}_{01} \tilde{x}_{2}+\tilde{a}_{11} \tilde{x}_{1} \tilde{x}_{2}+\tilde{a}_{20} \tilde{x}_{1}^{2}+\tilde{a}_{02} \tilde{x}_{2}^{2}
$$

For the solution of equation (2), let us construct a neural structure in which the parameters of the network are coefficients $\tilde{a}_{00}, \tilde{a}_{10}, \tilde{a}_{01}, \tilde{a}_{11}, \tilde{a}_{20}$, and $\tilde{a}_{02}$. The structure of the NN will therefore have four inputs and one output (Fig 5).

Using the $\mathrm{NN}$ structure, we are training network parameters. For $\alpha=0$, we receive the following expressions:

$$
\begin{aligned}
\frac{\partial E_{1}}{\partial a_{001}} & =\sum_{j=1}^{k}\left(y_{j 1}-t_{j 1}\right) ; \frac{\partial E_{2}}{\partial a_{002}}=\sum_{j=1}^{k}\left(y_{j 2}-t_{j 2}\right) ; \\
\frac{\partial E_{1}}{\partial a_{101}} & =\sum_{j=1}^{k}\left(y_{j 1}-t_{j 1}\right) x_{11} ; \frac{\partial E_{2}}{\partial a_{102}}=\sum_{j=1}^{k}\left(y_{j 2}-t_{j 2}\right) x_{12} ; \\
\frac{\partial E_{1}}{\partial a_{011}} & =\sum_{j=1}^{k}\left(y_{j 1}-t_{j 1}\right) x_{21} ; \frac{\partial E_{2}}{\partial a_{012}}=\sum_{j=1}^{k}\left(y_{j 2}-t_{j 2}\right) x_{22} ; \\
\frac{\partial E_{1}}{\partial a_{111}} & =\sum_{j=1}^{k}\left(y_{j 1}-t_{j 1}\right) x_{11} x_{21} ; \frac{\partial E_{2}}{\partial a_{112}}=\sum_{j=1}^{k}\left(y_{j 2}-t_{j 2}\right) x_{12} x_{22} ;
\end{aligned}
$$

$$
\begin{aligned}
& \frac{\partial E_{1}}{\partial a_{201}}=\sum_{j=1}^{k}\left(y_{j 1}-t_{j 1}\right) x_{11}^{2} ; \frac{\partial E_{2}}{\partial a_{202}}=\sum_{j=1}^{k}\left(y_{j 2}-t_{j 2}\right) x_{12}^{2} ; \\
& \frac{\partial E_{1}}{\partial a_{021}}=\sum_{j=1}^{k}\left(y_{j 1}-t_{j 1}\right) x_{21}^{2} ; \frac{\partial E_{2}}{\partial a_{022}}=\sum_{j=1}^{k}\left(y_{j 2}-t_{j 2}\right)^{2} x_{22}^{2}
\end{aligned}
$$

It is necessary to note that at negative values of the coefficients $\tilde{a}_{r s}\left(\tilde{a}_{r s}<0\right)$, the calculation formulas of the expressions that include parameters $\tilde{a}_{r s}$ in equation (3) and correction of the given parameter in equation (4) will change the form. For example, if we allow $\tilde{a}_{r s}<0$, then the calculations of the formula of the fourth expression, which includes in equation (3), will take the following form:

$$
y_{41}=a_{111} x_{12} x_{22} ; y_{42}=a_{112} x_{12} x_{21},
$$

and the correction formulas will be

$$
\begin{gathered}
\frac{\partial E_{1}}{\partial a_{111}}=\sum_{j=1}^{k}\left(y_{j 1}-t_{j 1}\right) x_{12} x_{22} ; \\
\frac{\partial E_{2}}{\partial a_{112}}=\sum_{j=1}^{k}\left(y_{j 2}-t_{j 2}\right) x_{11} x_{21} ;
\end{gathered}
$$

For value $\alpha=1$ we shall receive

$$
\begin{gathered}
\frac{\partial E_{3}}{\partial a_{003}}=\sum_{j=1}^{k}\left(y_{j 3}-t_{j 3}\right) ; \quad \frac{\partial E_{3}}{\partial a_{113}}=\sum_{j=1}^{k}\left(y_{j 3}-t_{j 3}\right) x_{13} x_{23} ; \\
\frac{\partial E_{3}}{\partial a_{103}}=\sum_{j=1}^{k}\left(y_{j 3}-t_{j 3}\right) x_{13} ; \quad \frac{\partial E_{3}}{\partial a_{203}}=\sum_{j=1}^{k}\left(y_{j 3}-t_{j 3}\right) x_{13}^{2} ; \\
\frac{\partial E_{3}}{\partial a_{013}}=\sum_{j=1}^{k}\left(y_{j 3}-t_{j 3}\right) x_{23} ; \quad \frac{\partial E_{3}}{\partial a_{023}}=\sum_{j=1}^{k}\left(y_{j 3}-t_{j 3}\right) x_{23}^{2} ;
\end{gathered}
$$

As the result of training (4) and (5), we find parameters of the network satisfying the knowledge base with required training quality.

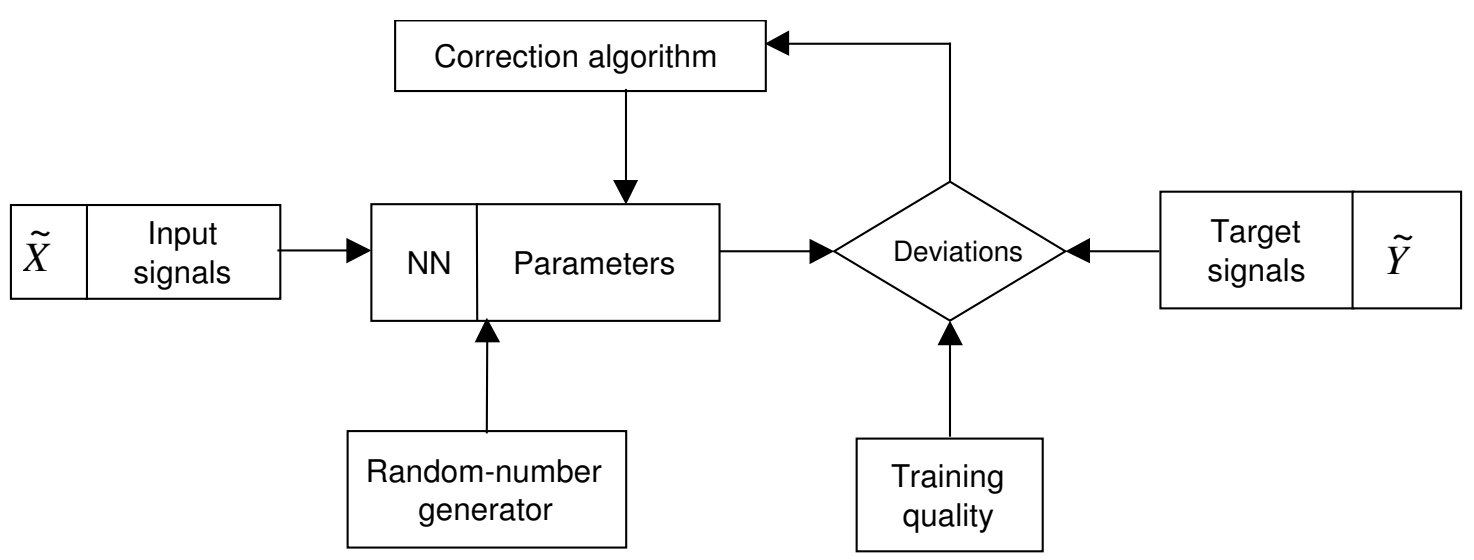

Fig 3. System for network-parameter (weights, threshold) training (with feedback) 


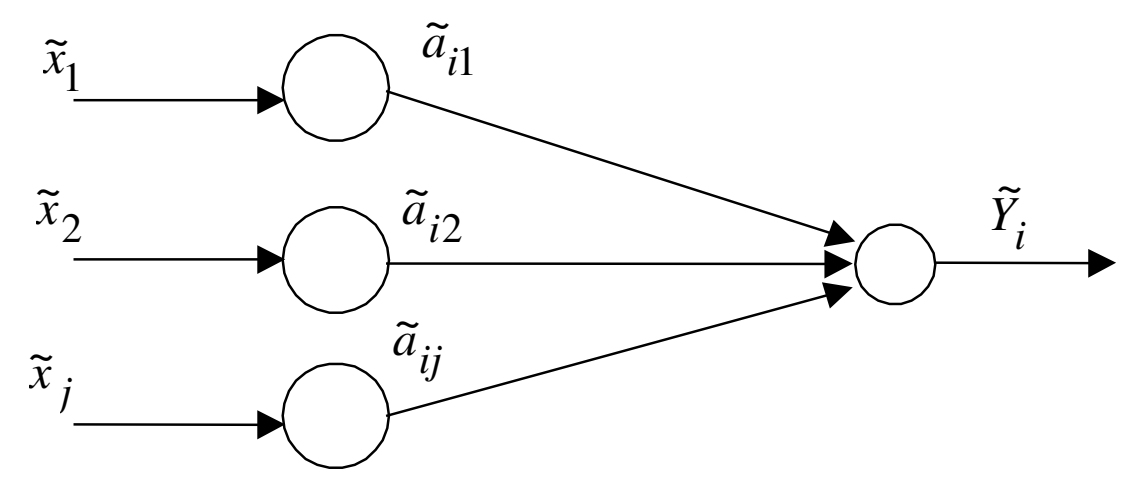

Fig 4. Neural network structure for multiple linear regression equation

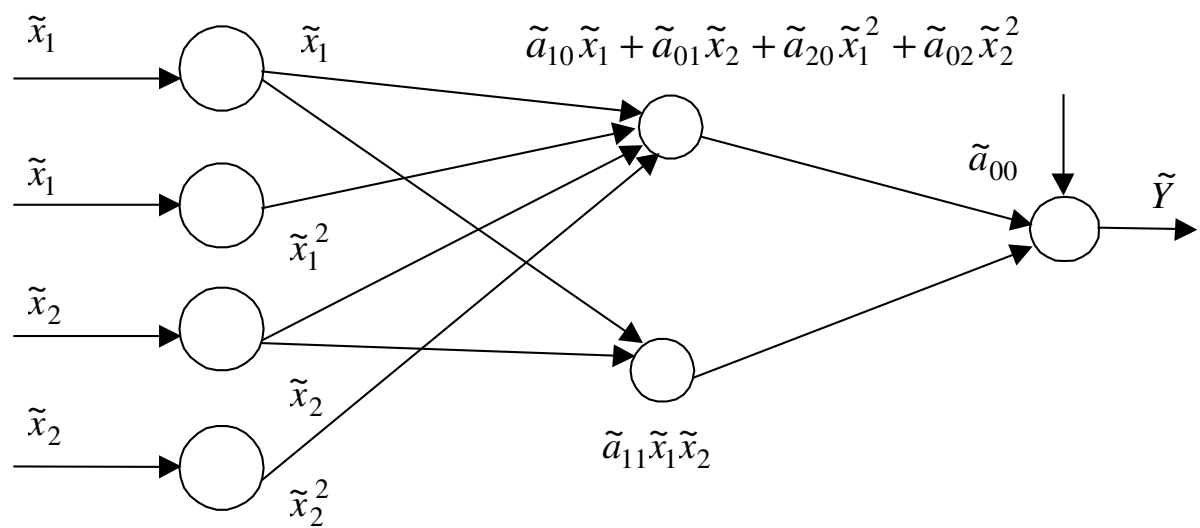

Fig 5. Structure of neural network for second-order regression equation

\section{Monitoring GTE condition by fuzzy statistical analysis (First stage)}

The choice of the GTE technical condition model (linear or non-linear) may be made with the help of the complex comparison analysis of fuzzy correlation coefficients $\tilde{r}_{x y}$ and fuzzy correlation ratios $\tilde{\rho}_{y / x}$. The following cases are therefore possible:

a) if $\tilde{y}$ is not dependent on $\tilde{x}, \tilde{\rho}_{y / x} \simeq \tilde{0}$ (fuzzy zero);

b) if there is the fuzzy functional linear dependence of $\tilde{y}$ on $\tilde{x}, \tilde{r}_{x y} \cong \tilde{\rho}_{y / x} \cong \tilde{1}$ (fuzzy one);

c) if there is the fuzzy functional non-linear dependence of $\tilde{y}$ on $\tilde{x}, \tilde{r}_{x y} \tilde{<} \tilde{\rho}_{y / x} \tilde{=} \tilde{1}$;

d) if there is the fuzzy linear regression of $\tilde{y}$ from $\tilde{x}$ but there is no functional dependence, $\tilde{r}_{x y} \simeq \tilde{\rho}_{y / x} \tilde{<} \tilde{1}$;

e) if there is some fuzzy non-linear regression of $\tilde{y}$ from $\tilde{x}$, but there is no functional dependence, $\tilde{r}_{x y} \tilde{<} \tilde{\rho}_{y / x} \tilde{<} \tilde{1}$,

where $\tilde{<}$ and $\cong$ are fuzzy relations that are determined by the appropriate membership functions $\mu\left(r_{x y}\right)$ and $\mu\left(\rho_{y / x}\right)$.
The values of $\tilde{r}_{x y}$ and $\tilde{\rho}_{y / x}$ may be estimated as follows

$$
\tilde{r}_{x y}=\frac{\tilde{R}}{\tilde{R}_{x} \otimes \tilde{R}_{y}} ; \tilde{\rho}_{y / x}=\sqrt{1-\frac{\tilde{\sigma}_{y / x}^{2}}{\tilde{\sigma}_{y}^{2}}}
$$

where

$$
\begin{gathered}
\tilde{R}=\sum \tilde{x} \otimes \tilde{y}-\frac{1}{n} \sum \tilde{x} \otimes \sum \tilde{y} \\
\tilde{R}_{x}=\sqrt{\sum \tilde{x}^{2}-\frac{1}{n}\left(\sum \tilde{x}\right)^{2}} \\
\tilde{R}_{y}=\sqrt{\sum \tilde{y}^{2}-\frac{1}{n}\left(\sum \tilde{y}\right)^{2}}
\end{gathered}
$$

$\tilde{\sigma}_{y / x}^{2}=\frac{\sum\left(\tilde{y}-\tilde{\bar{y}}_{x}\right)^{2}}{n}$ is residual dispersion $\tilde{y}$, which is formed by the influence of $\tilde{x} ; \quad \tilde{\sigma}_{y}^{2}=\frac{\sum(\tilde{y}-\tilde{\bar{y}})^{2}}{n}$ is general variation, which takes into account all influences of fuzzy factors; $\tilde{\bar{y}}_{x}$ is the partial fuzzy average value of $\tilde{y}$, which is formed by the influence of $\tilde{x}$; and $\tilde{\bar{y}}$ is the general fuzzy average value of $\tilde{y}$. 
However, research carried out shows that the distributions of the work parameters of GTE have an unstable character (fuzzy character). Therefore, it is necessary to note that the correct application of the fuzzy correlation-regression approach demands the analysis of the fuzzy characteristics of the distributions of the work parameters of GTE. With this purpose in mind, one must carry out a fuzzy analysis of the distribution of GTE work parameters on the basis of fuzzy values of skewness and kurtosis coefficients using the following formulas (Tabs 1-2; Appendix):

$$
\tilde{A}(P)=\frac{\tilde{M}(P)_{3}}{\tilde{S}_{n}^{3}} ; \tilde{E}(P)=\frac{\tilde{M}(P)_{4}}{\tilde{S}_{n}^{4}}-3
$$

where $\tilde{A}(P)$ and $\tilde{E}(P)$ are fuzzy skewness and kurtosis coefficients of the GTE work parameter $P$ (e.g. for $\begin{array}{lllll}\text { output } y & \text { or input } x & \text { parameter); }\end{array}$ $\tilde{M}(P)_{3}=\frac{1}{n} \sum_{i=1}^{n}\left(\tilde{P}_{i}-\tilde{\bar{P}}_{n}\right)^{3}$ is the fuzzy third central moment of parameter $P ; \tilde{M}(P)_{4}=\frac{1}{n} \sum_{i=1}^{n}\left(\tilde{P}_{i}-\tilde{\bar{P}}_{n}\right)^{4}$ is the fuzzy fourth central moment of parameter $P$; and $\tilde{S}_{n}^{2}=\frac{1}{n-1} \sum_{i=1}^{n}\left(\tilde{P}_{i}-\tilde{\bar{P}}_{n}\right)$ is the fuzzy standard deviation of parameter

$P \quad$ (e.g. $\quad H, M, T_{H}^{*}, p_{H}^{*}, n_{L P}, T_{4}^{*}, G_{T}, p_{T}, \quad p_{M}, P$ $\left.T_{M}, V_{B S}, V_{F S}\right)$.

At known membership functions of fuzzy skewness $\tilde{A}$ and kurtosis $\tilde{E}$ coefficients, a check of the distributions of the fuzzy parameters of GTE work can be carried out with the help of the fuzzy $\tilde{\chi}^{2}$ criterion (fuzzy Chi-square test criterion)

$$
\tilde{\chi}^{2}=\frac{\tilde{A}^{2}(P)}{6 / n}+\frac{(\tilde{E}(P)-3)^{2}}{24 / n}
$$

The use of the given formula requires finding the values of $\tilde{A}$ and $\tilde{E}$ that correspond to cores $d_{A}=1$ and $d_{E}=1$, where

$$
\begin{aligned}
& d_{A}=\underset{A \subset \mathrm{max}}{\mu_{\mathrm{A}}(A),} \\
& d_{E}=\underset{E \subset \mathrm{A}}{\max _{\mathrm{E}}(E) .}
\end{aligned}
$$

Here $A$ and $E$ elements of fuzzy $\mathrm{A}$ and $\mathrm{E}$ sets, $\mu_{\mathrm{A}}$ and $\mu_{\mathrm{E}}$ membership functions $A$ and $E$ fuzzy sets to $\mathrm{A}$ and $\mathrm{E}$ sets.

The significance level of the fuzzy multiple correlation coefficient and fuzzy regression can be checked with the help of the so-called fuzzy $\tilde{F}$ criterion (fuzzy Fisher test)

$$
\begin{aligned}
& \tilde{F}[m, n-(m+1)]= \\
& =\left([n-(m+1)] \tilde{R}^{2}\right) /\left(m\left(1-\tilde{R}^{2}\right)\right)
\end{aligned}
$$

where $\tilde{R}$ is the fuzzy coefficient of multiple correlation (Fig 7 and Tab 3; Appendix);

$$
\tilde{R}_{Y . X_{1} X_{2} \ldots X_{n}}=\sqrt{\begin{array}{l}
1-\left(1-\tilde{r}_{Y X_{1}}^{2}\right)\left(1-\tilde{r}_{Y X_{2} X_{1}}^{2}\right)\left(1-\tilde{r}_{Y X_{3} X_{1} X_{2}}^{2}\right) \ldots \\
\ldots\left(1-\tilde{r}_{Y X_{n} X_{1} X_{2} \ldots X_{n-1}}^{2}\right)
\end{array}}
$$

$n$ is the number of measurements; $m$ is the number of factors (e.g. $H, M, T_{H}^{*}, p_{H}^{*}, n_{L P}, T_{4}^{*}, G_{T}, p_{T}, p_{M}, T_{M}$, $\left.V_{B S}, V_{F S}\right)$, and $\tilde{r}$ is the values of fuzzy correlation coefficients with corresponding to cores $d_{r}=1$

$$
d_{r}=\underset{r \subset r}{\max } \mu_{r}(r)
$$

where $r$ is an element (correlation coefficient) of fuzzy set $r$ and $\mu_{r}$ is membership functions $r$ to set $r$.

$\tilde{F}$ values calculated according to this formula are comparing with tabulated values (critical values) $F_{c r}$ of Fisher distribution corresponding to the chosen reliability degree $P$ (or with significance level $\alpha=1-P$ ). Thus that $\tilde{F}^{*}$ values is exposed to comparison with $F_{c r}$ which corresponds membership functions core

$$
d_{F}=\max \underset{f \subset F}{\mu_{F}(f)=1}
$$

where $f$ is an element of the fuzzy set $F$ and $\mu_{F}$ is the membership function of $f$ to set $F$.

If $\tilde{F}^{*}>F_{c r}$, the fuzzy coefficient of multiple correlation $\tilde{R}$ admits significant at level $\alpha$.

\section{Monitoring GTE condition using regre- ssion analysis and Kalman-type filter (Second stage)}

The analysis shows that during following $60-120$ measurements occurs the approach of individual parameters values of GTE work to normal distribution. Therefore, at the accumulation of certain information in the second stage, GTE conditions are estimated with the help of mathematical statistics. Here the given and enumerated to the one GTE work mode and standard atmosphere parameters are controlled on conformity to their calculated admissible and possible ranges.

Further by means of the Least Squares Method (LSM), the multiple linear regression models of changes in GTE conditions are identified. These models are made for each correct subcontrol engine of the fleet during the initial period of operation. On the basis of the analysis of the values of the regression coefficient (coefficients of 
influence) of all engine's multiple regression models with the help of mathematical statistics base and admissible range of coefficients (Abdullayev et al. 2005, Pashayev et al. 2004b).

Monitoring GTE condition using regression analysis and Kalman-type filter (second stage) is presented by A. Pashayev (Pashayev et al. 2004a).

\section{Monitoring GTE condition using results of complex analysis of first and second stages (Third stage)}

On the third stage (for more than 120 measurements) by the LSM estimation conducts the detail analysis of GTE conditions. The essence of those procedures is making an actual model (multiple linear regression equation) of the conditions of GTE and comparing actual coefficients of influence (regression coefficients) with their base admissible ranges. The reliability of diagnostic results in this stage is high and equal to $0.95 \div 0.99$. The influence coefficient's values going out the mentioned ranges allows make conclusion about the meaning changes of physical process influence on the concrete GTE work parameters. The stable going out one or several coefficient's influences beyond the abovementioned range affirms about additional feature of incorrectness and permits to determine address and possible reason of faults. To receive stable (robust) estimations by LSM, ridge-regression analysis is therefore used.

With the view of forecasting GTE conditions, the regression coefficients are approximated by second and third degree polynomials.

As an example of the application of the aforementioned method, changes in the conditions of a GTE (aviation engine D-30KU-154) were investigated. At the preliminary stage, when the number of measurements is $N \leq 60$, the technical condition of the GTE is described by the fuzzy linear regression equation (1). The identification of the fuzzy linear model of the GTE is made with help of NN, the structure of which is given in figure 2. The GTE exhaust gas temperature is therefore accepted as the output parameter of the GTE model

$$
\begin{aligned}
& \quad\left(\tilde{T}_{4}^{*}\right)_{i n i}=\tilde{a}_{1} \tilde{H}+\tilde{a}_{2} \tilde{M}+\tilde{a}_{3} \tilde{T}_{H}^{*}+\tilde{a}_{4} \tilde{n}_{L P}+\tilde{a}_{5} \tilde{p}_{T}+\tilde{a}_{6} \tilde{p}_{M}+ \\
& \quad+\tilde{a}_{7} \tilde{T}_{M}+\tilde{a}_{8} \tilde{G}_{T}+\tilde{a}_{9} \tilde{V}_{F S}+\tilde{a}_{10} \tilde{V}_{B S}+\tilde{a}_{11} \tilde{p}_{H}^{*} \\
& D=\left(T_{4}^{*}\right)_{a c t}=a_{1}^{\prime} H+a_{2}^{\prime} M+a_{3}^{\prime} T_{H}^{*}+a_{4}^{\prime} n_{L P}+a_{5}^{\prime} p_{T}+a_{6}^{\prime} p_{M}+ \\
& +a_{7}^{\prime} T_{M}+a_{8}^{\prime} G_{T}+a_{9}^{\prime} V_{F S}+a_{10}^{\prime} V_{B S}+a_{11}^{\prime} p_{H}^{*}
\end{aligned}
$$

On the subsequent stage for each current measurement's $N>60$, when observes the normal distribution of the engine work parameters, GTE temperature condition describes by linear regression equation (6) which parameters is estimated by recurrent algorithm (Pashayev et al. 2004).

As the result of the research conducted for the varied technical condition of the considered engine was revealed certain dynamics of the correlation and regression coefficients values changes which is given in figures 6 and 8 (Appendix).

The basic characteristics of correlation coefficients (Fig 6; Appendix) show the necessity of using fuzzy NN for the processing of flight information. In that case correct application of this approach on describing up of the GTE technical condition changes is possible by fuzzy linear or non-linear model (Pashayev et al. 2004a, Abdullayev et al. 2005).

For the third stage was made the following admission of regression coefficients (influence coefficients of various parameters) of various parameters on GTE exhaust gas temperature in linear multiple regression equation (1): frequency of engine rotation (RPM of low pressure compressor) $-0.596 \div 0.622$; fuel pressure - $1.16 \div 1.25$; fuel flow - $0.0240 \div 0.0252$; oil pressure - $11.75 \div 12.45$; oil temperature - $1.1 \div 1.2$; vibration of the forward support $-3.0 \div 5.4$; vibration of the back support - $1.2 \div 1.9$; atmosphere pressure $112 \div 128$; atmosphere temperature $-(-0.84) \div(-0.64)$; flight speed (Mach number) - 57.8 $\div 60.6$; and flight altitude $-0.00456 \div 0.00496$. Within the limits of the specified admissions of regression coefficients was carried out approximation of the their (regression coefficients) current values by the polynomials of the second and third degree with help LSM and with use cubic splines (Fig 8; Appendix).

\section{Conclusions}

1. The GTE technical condition combined diagnosing approach is offered, which is based on engine work fuzzy and non-fuzzy parameters estimation with the help of Soft Computing methods (Fuzzy Logic and Neural Networks) and the confluent analysis.

2. It is shown that the use of soft computing methods to recognise the technical condition of GTE has certain advantages in comparison with traditional probabilitystatistical approaches. First of all, it is connected by that the offered methods may be used irrespective of the kind of GTE work parameters distributions. As at the early stage of the engine work, because of the limited amount of information, the kind of distribution of parameters is difficult to establish.

3. By complex analysis it is established that:

- between the fuzzy thermodynamic and mechanical parameters of GTE operation, there are certain fuzzy relations which degree in operating process and in dependence of fuzzy diagnostic situation changes' dynamics increases or decreases,

- for various situations of malfunctions development is observed different fuzzy dynamics (changes) of connections (correlation coefficients) between engine work fuzzy parameters in operating, caused by occurrence or disappearance of factors influencing GTE technical condition,

- for improvement of accepted decisions accuracy about GTE technical condition is expedient to apply fuzzy 
statistics in offered condition monitoring system.

The suggested methods make it possible not only to diagnose but also to predict the safe engine runtime. These methods give tangible results and can be recommended for practical application both for automatic engine diagnostic systems in which the handle records are used as initial information and for onboard systems of engine work control.

\section{References}

Abasov, M. T.; Sadiqov, A. H.; Aliyarov, R. Y. 1998. Fuzzy neural networks in the system of oil and gas geology and geophysics. In Third International Conference on Application of Fuzzy Systems and Soft Computing. Wiesbaden, Germany, 108-117.

Abdullayev, P. S.; Pashayev, A. M.; Askerov, D. D. et al. 2005. Aircraft gas turbine engines' technical condition identification system. In ASME TURBO EXPO 2005: Power for Land, Sea and Air Conference, June 6-9, 2005, Reno-Tahoe, Nevada, USA. Paper GT2005-69072.

Doroshko, S. M. 1984. The control and diagnosing of GTE technical condition on vibration parameters. Moscow: Transport. $128 \mathrm{p}$.

Hassoun, M. H. 1995. Fundamentals of Artificial Neutral Networks. A Bradford Book, The MIT Press, Cambridge, Massachusetts, London, England.

Fuzzy sets, neural networks and soft computing.
1994. No 4. Ed. by R .R Yager, L. A Zadeh. N.Y.: VAN Nostrand Reinhold.

Ivanov L.A. et al. 1984. The technique of civil aircraft GTE technical condition diagnosing and forecasting on registered rotor vibrations parameters changes in service. Moscow: GosNII GA. 88 p.

Pashayev, A. M.; Askerov, D. D.; Sadiqov, R. A. et al. 2004a. Fuzzy-neural approach for aircraft gas turbine engines diagnosing. In AIAA 1st Intelligent Systems Technical Conference (Sept. 20-22, 2004, Chicago, Illinois). AIAA-2004-6222.

Pashayev, A. M.; Sadiqov, R. A.; Abdullayev, P. S. 2003. Complex identification technique of aircraft gas turbine engine's health. In ASME TURBO EXPO 2003: Power for Land, Sea and Air Conference, June 16-19, 2003, Atlanta, Georgia, USA. Paper GT200338704.

Pashayev, A. M.; Askerov, D. D.; Sadiqov, R. A. et al. 2004b. Aviation gas turbine engines technical condition diagnosing system. In Abstracts of XII AllRussian inter-institute science-technical conference "Gas turbine and combined installations and engines" dedicated to 175-year MSTU nam. N.E. BAUMAN and 55-year department E-3, N.E. BAUMAN MSTU, 24-26 November, 2004, Moscow, Russia. Moscow, 209-210.

\section{AVIACINIŲ DUJŲ TURBININIŲ VARIKLIŲ TECHNINIŲ SAVYBIŲ IDENTIFIKAVIMO SISTEMA}

A. Pashayev, D. Askerov, R. Sadiqov, P. Abdullayev

S a n tra k a

Straipsnyje atskleidžiamas tikimybinio-statistinio metodo nepagrịstumas diagnozuojant dujų turbininius variklius, kai informacija yra netiksli, ribota ir neapibrěžta. Parodytas technologijos Soft Computing taikymo efektyvumas. Taikant netikslios statistikos, netikslios logikos ir neuroniniu tinklu tikslius metodus dujų turbininių variklių diagnozavimui atliekamas daugiamačių tiesinių ir netiesinių modelių (regresijos lygčiu), gautų iš netikslių statistinių duomenų, apmokymas. Taikant aprašytą metodą buvo atlikta pradèto eksploatuoti turbininio variklio šiluminès būsenos analizė.

Reikšminiai žodžiai: aviacinis dujų turbininis variklis, netiksli logika ir neuroniniai tinklai, netiksli statistika, netikslus daugialypės koreliacijos koeficientas. 
A. Pashayev, D. Askerov, R. Sadiqov, P. Abdullayev. Identification system for the technical condition of gas turbine engines of aircraft

\section{Appendix}

Table 1. Basic characteristics of fuzzy skewness coefficients

\begin{tabular}{|c|c|c|c|c|c|}
\hline $\begin{array}{c}\text { Coefficients } \\
A(x) \\
\text { of GTE work } \\
\text { parameters }\end{array}$ & $\begin{array}{c}\text { Mean of } \\
\text { Coeficients }\end{array}$ & $\begin{array}{c}\text { Standard } \\
\text { deviation } \\
A(x)\end{array}$ & $\begin{array}{c}\text { Minimum of } \\
\text { coefficients } A(x)\end{array}$ & $\begin{array}{c}\text { Maximum of } \\
\text { coefficients } \\
A(x)\end{array}$ & $\begin{array}{c}\text { Characteristics of fuzzy } \\
\text { skewness coefficients } A(x), \\
\tilde{A}(x)=(A(x), \alpha, \beta)\end{array}$ \\
\hline$A\left(n_{L P}\right)$ & -0.23241 & 0.321967 & -1.11971 & 0.336825 & $(0.107,1.227,0.230)$ \\
\hline$A\left(T_{4}^{*}\right)$ & 0.50122 & 0.284556 & -1.11657 & 1.040502 & $(0.359,1.476,0.681)$ \\
\hline$A\left(p_{T}^{*}\right)$ & -0.18664 & 0.540657 & -1.17936 & 0.9457 & $(-0.508,0.671,1.454)$ \\
\hline$A\left(p_{M}^{*}\right)$ & 0.99583 & 0.363439 & -0.23443 & 1.45711 & $(1.3685,1.603,0.089)$ \\
\hline$A\left(T_{M}^{*}\right)$ & 0.38082 & 0.403829 & -0.7176 & 1.173577 & $(-0.021,0.697,1.195)$ \\
\hline$A\left(G_{T}\right)$ & 0.26658 & 0.383172 & -1.37908 & 1.470736 & $(0.121,1.50,1.35)$ \\
\hline$A\left(V_{F S}\right)$ & 0.77308 & 0.256291 & -0.16279 & 1.181255 & $(1.0395,1.202,0.142)$ \\
\hline$A\left(V_{B S}\right)$ & 0.4596 & 0.293852 & -0.57932 & 1.078241 & $(0.5545,1.134,0.524)$ \\
\hline$A(H)$ & -0.26294 & 0.403748 & -1.86149 & 0.278945 & $(0.0535,1.915,0.225)$ \\
\hline$A(M)$ & -1.62084 & 0.576057 & -2.83662 & 1.485629 & $(-1.244,1.593,2.73)$ \\
\hline$A\left(T_{H}^{*}\right)$ & 0.96686 & 0.560755 & -1.03063 & 1.65627 & $(1.515,2.546,0.141)$ \\
\hline$A\left(p_{H}^{*}\right)$ & 0.02898 & 0.420972 & -0.57615 & 1.554167 & $(0.433,1.009,1.121)$ \\
\hline
\end{tabular}

Table 2. Basic characteristics of fuzzy kurtosis coefficients

\begin{tabular}{|c|c|c|c|c|c|}
\hline $\begin{array}{c}\text { Coefficients } \\
E(x) \\
\text { of GTE work } \\
\text { parameters }\end{array}$ & $\begin{array}{c}\text { Mean of } \\
\text { coefficients } \\
E(x)\end{array}$ & $\begin{array}{c}\text { Standard } \\
\text { deviation } \\
E(x)\end{array}$ & $\begin{array}{c}\text { Minimum of } \\
\text { coefficients } \\
E(x)\end{array}$ & $\begin{array}{c}\text { Maximum of } \\
\text { coefficients } \\
E(x)\end{array}$ & $\begin{array}{c}\text { Characteristics of fuzzy } \\
\text { skewness coefficients } E(x), \\
\tilde{E}(x)=(E(x), \alpha, \beta)\end{array}$ \\
\hline$E\left(n_{L P}\right)$ & 0.051116 & 0.45444 & -1.81492 & 0.658448 & $(0.268,2.083,0.390)$ \\
\hline$E\left(T_{4}^{*}\right)$ & -0.25381 & 0.276423 & -1.4534 & -0.01302 & $(-0.089,1.364,0.076)$ \\
\hline$E\left(p_{T}^{*}\right)$ & 0.050607 & 0.679819 & -1.7868 & 0.914802 & $(0.773,2.560,0.142)$ \\
\hline$E\left(p_{M}^{*}\right)$ & -0.37732 & 0.332528 & -1.79575 & 0.124665 & $(-0.2795,1.516,0.404)$ \\
\hline$E\left(T_{M}^{*}\right)$ & -0.01636 & 0.415829 & -1.8803 & 0.484257 & $(0.2355,2.116,0.249)$ \\
\hline$E\left(G_{T}\right)$ & 0.306218 & 0.488186 & -1.59482 & 0.864367 & $(0.6055,2.2,0.259)$ \\
\hline$E\left(V_{F S}\right)$ & -0.8707 & 0.211368 & -1.9007 & -0.54713 & $(-0.7605,1.14,0.213)$ \\
\hline$E\left(V_{B S}\right)$ & 0.118197 & 0.570606 & -1.82124 & 1.583317 & $(-0.0295,1.792,1.613)$ \\
\hline$E(H)$ & 1.291274 & 0.831258 & -2.17252 & 4.21139 & $(0.851,3.024,3.36)$ \\
\hline$E(M)$ & 3.18879 & 1.860652 & -0.89764 & 7.868297 & $(1.8705,2.768,5.998)$ \\
\hline$E\left(T_{H}^{*}\right)$ & 0.080223 & 0.732302 & -1.6196 & 1.813923 & $(-0.3545,1.265,2.168)$ \\
\hline$E\left(p_{H}^{*}\right)$ & 0.519337 & 0.56576 & -1.96438 & 2.77291 & $(0.2795,2.244,2.493)$ \\
\hline
\end{tabular}

Table 3. Basic characteristics of fuzzy multiple correlation coefficient

\begin{tabular}{|c|c|c|c|c|c|}
\hline $\begin{array}{c}\text { Coefficient } \\
\text { of multiple } \\
\text { determination }\end{array}$ & $\begin{array}{c}\text { Mean of } \\
\text { coefficient }\end{array}$ & $\begin{array}{c}\text { Standard } \\
\text { deviation }\end{array}$ & $\begin{array}{c}\text { Minimum of } \\
\text { coefficient }\end{array}$ & $\begin{array}{c}\text { Maximum of } \\
\text { coefficient }\end{array}$ & $\begin{array}{c}\text { Characteristics of fuzzy coefficient } R^{2}, \\
\tilde{R}^{2}=\left(R^{2}, \alpha, \beta\right)\end{array}$ \\
\hline$R^{2}$ & 0.989298 & 0.000137 & 0.989038 & 0.989576 & $(0.989243,0.000205,0.000333)$ \\
\hline
\end{tabular}




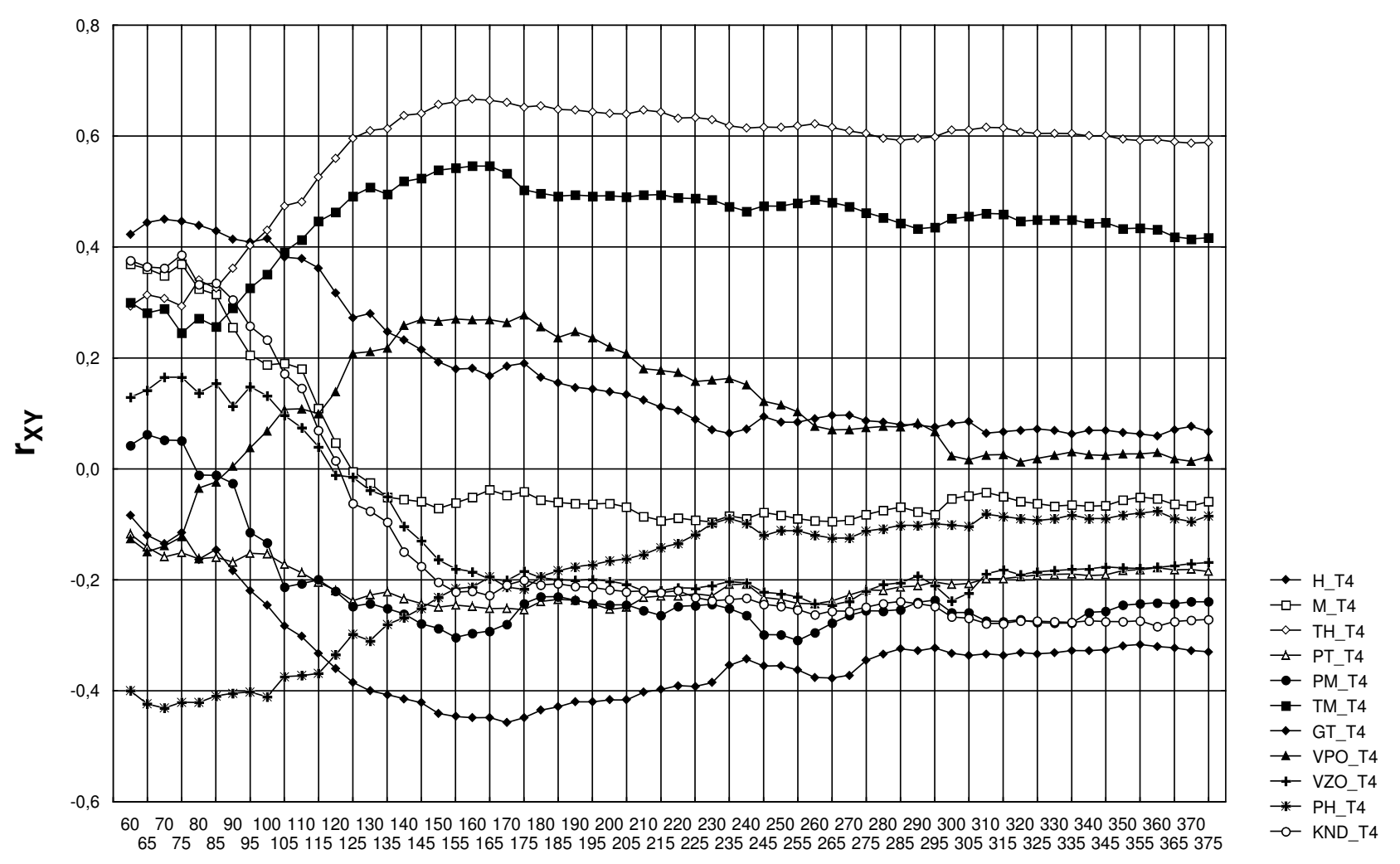

Fig 6. Change in values of correlation coefficient (relation values) between parameters included in linear multiple regression equation $D=\left(T_{4}^{*}\right)_{a c t}$ in GTE operation: a) H_T4-relation between $H$ and $T_{4}^{*}$ (correlation coefficient $R_{H, T_{4}^{*}}$ ); b) M_T4-relation between $M$ and $T_{4}^{*}$ (correlation coefficient $r_{M, T_{4}^{*}}$ ); c) TH_T4-relation between $T_{H}^{*}$ and $T_{4}^{*}$ (correlation coefficient $r_{T_{H}^{*}, T_{4}^{*}}$ ); d) PT_T4-relation between $p_{T}$ and $T_{4}^{*}$ (correlation coefficient $r_{p_{T}, T_{4}^{*}}$ ); e) PM_T4-relation between $p_{M}$ and $T_{4}^{*}$ (correlation coefficient $r_{p_{M}, T_{4}^{*}}$ ); f) TM_T4-relation between $T_{M}$ and $T_{4}^{*}$ (correlation coefficient $r_{T_{M}, T_{4}^{*}}$ ); g) GT_T4-relation between $G_{T}$ and $T_{4}^{*}$ (correlation coefficient $r_{G_{T}, T_{4}^{*}}$ ); h) VPO_T4-relation between $V_{F S}$ and $T_{4}^{*}$ (correlation coefficient $r_{V_{F S}, T_{4}^{*}}$ ); i) VZO_T4-relation between $V_{B S}$ and $T_{4}^{*}$ (correlation coefficient $r_{V_{B S}, T_{4}^{*}}$ ); j) PH_T4-relation between $p_{H}^{*}$ and $T_{4}^{*}$ (correlation coefficient $r_{p_{H}^{*}, T_{4}^{*}}$ ); k) KND_T4-relation between $n_{L P}$ and $T_{4}^{*}$ (correlation coefficient $r_{n_{L P}, T_{4}^{*}}$ ); N-number of measurements (scaling concerns to bottom numbers)

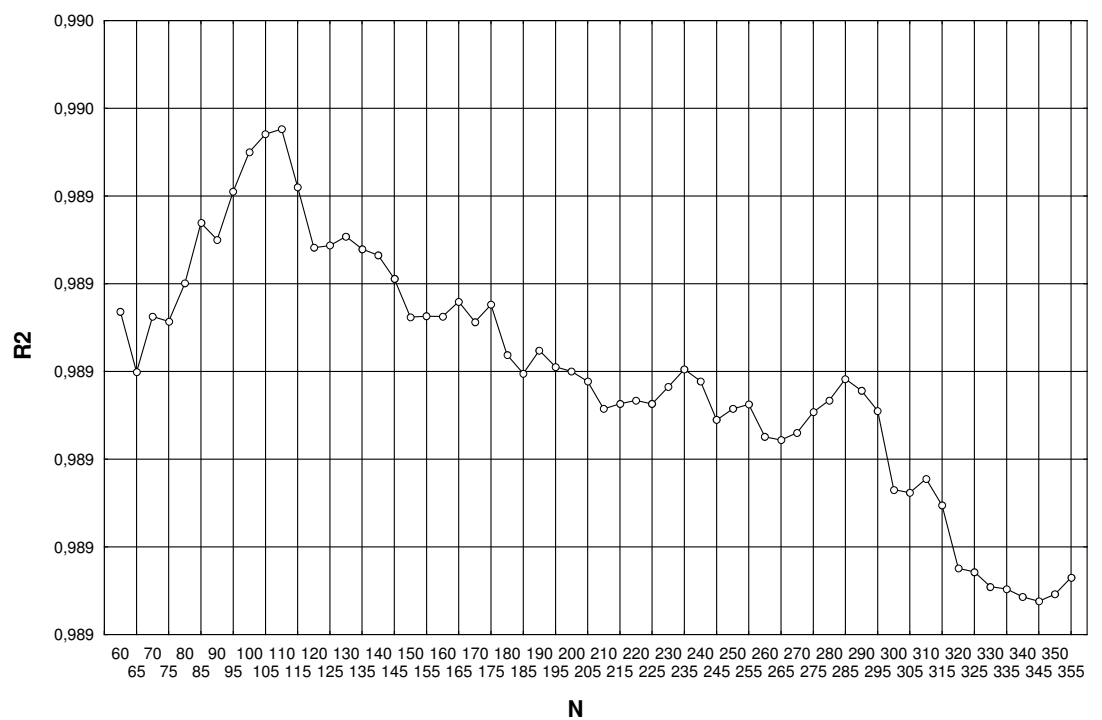

Fig 7. Change in fuzzy multiple correlation coefficient values in GTE operation: $R 2$-coefficient of multiple correlation, $\mathrm{N}$-number of measurements (scaling concerns to bottom numbers) 


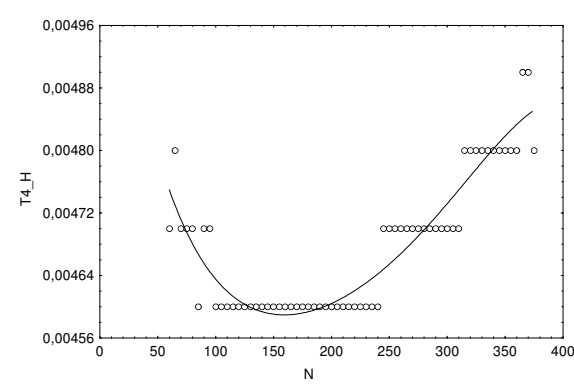

a)

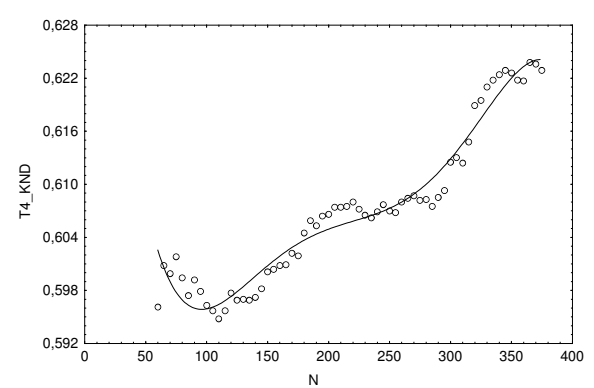

d)

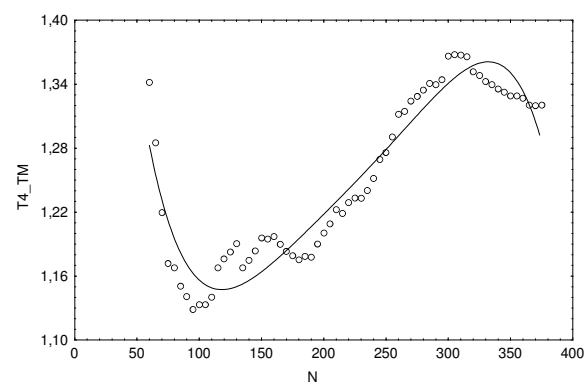

g)

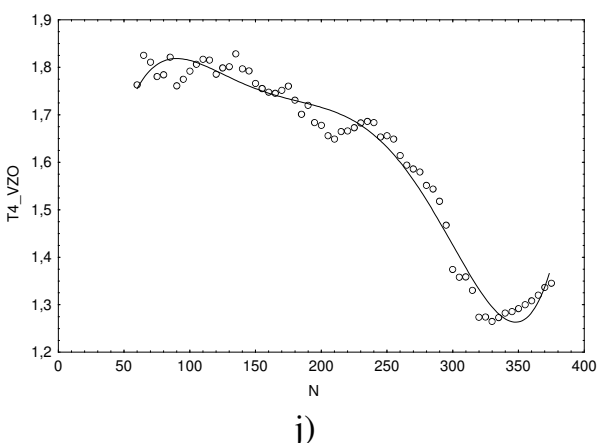

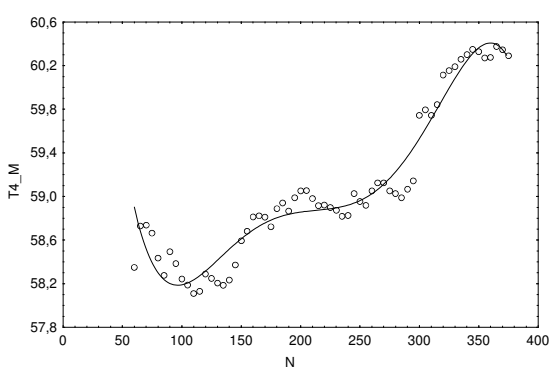

b)

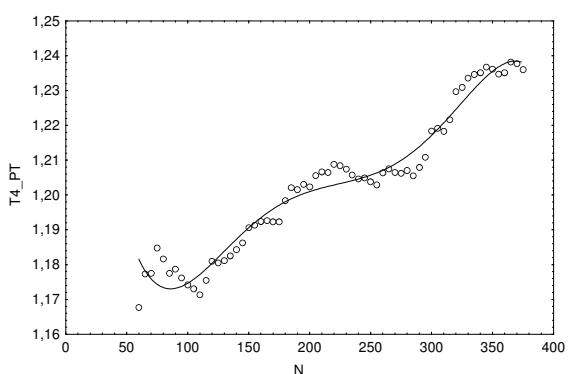

e)

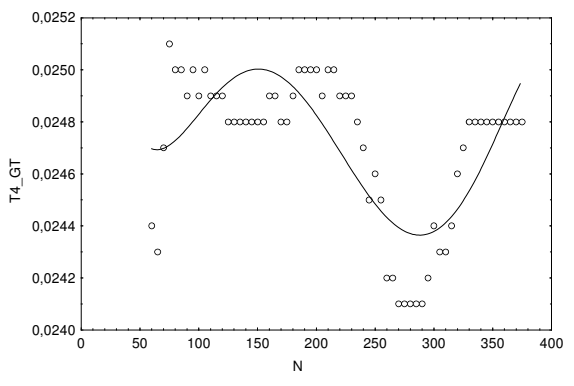

h)

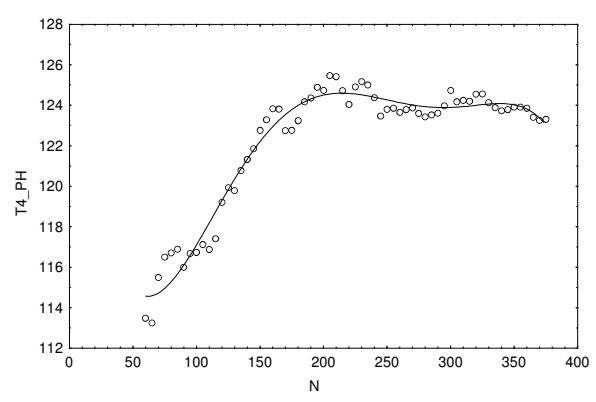

k)

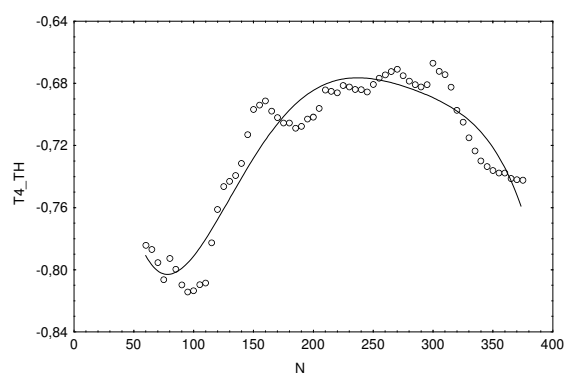

c)

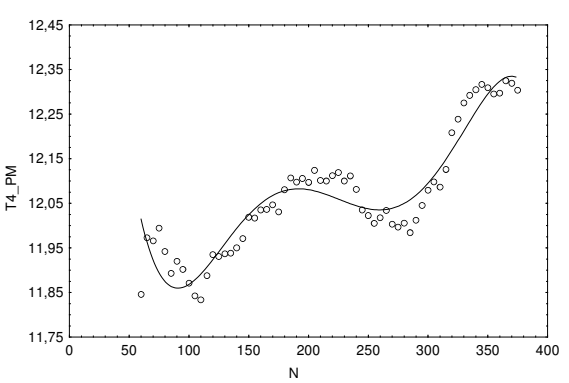

f)

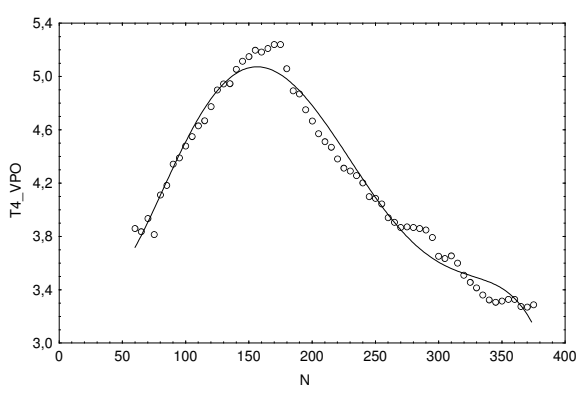

i)

Fig 8. Change in values of regression coefficient (influence) of parameters included in linear multiple regression equation $D=\left(T_{4}^{*}\right)_{a c t}$ to $T_{4}^{*}$ in GTE operation (continuation): a) T4_H - influence of $H$ on $T_{4}^{*}$ (coefficient $a_{1}^{\prime}$ ); b) T4_M - influence of $M$ on $T_{4}^{*}$ (coefficient $a_{2}^{\prime}$ ); c) T4_TH - influence of $T_{H}^{*}$ on $T_{4}^{*}$ (coefficient $a_{3}^{\prime}$ ); d) T4_KND - influence of $n_{L P}$ on $T_{4}^{*}$ (coefficient $\left.a_{4}^{\prime}\right)$; e) T4_PT - influence of $p_{T}$ on $T_{4}^{*}$ (coefficient $a_{5}^{\prime}$ ); f) T4_PM - influence of $p_{M}$ on $T_{4}^{*}$ (coefficient $a_{6}^{\prime}$ ); g) T4_TM influence of $T_{M}$ on $T_{4}^{*}$ (coefficient $a_{7}^{\prime}$ ); h) T4_GT - influence of $G_{T}$ on $T_{4}^{*}$ (coefficient $a_{8}^{\prime}$ ); i) T4_VPO - influence of $V_{F S}$ on $T_{4}^{*}($ coefficient $\left.a_{9}^{\prime}\right)$; j) T4_VZO - influence of $V_{B S}$ on $T_{4}^{*}\left(\right.$ coefficient $\left.a_{10}^{\prime}\right)$; k) T4_PH - influence of $p_{H}^{*}$ on $T_{4}^{*}\left(\operatorname{coefficient} a_{11}^{\prime}\right)$; $N-$ number of measurements 